\title{
A Path Analysis on Adherence to Antiretroviral Therapy among HIV/ AIDS Patients at Dr. Moewardi Hospital, Surakarta using Health Belief Model
}

\author{
Dyah Ayu Agustin 1,3), Afiono Agung Prasetyo²), Bhisma Murti3) \\ 1)School of Health Sciences Kendedes, Malang, East Java \\ 2)Faculty of Medicine, Universitas Sebelas Maret \\ 3)Masters Program in Public Health, Universitas Sebelas Maret
}

\begin{abstract}
Background: HIV / AIDS (Acquired Immune Deficiency Syndrome) is still a health problem in the world including in Indonesia. Approximately 36.7 people are infected with HIV in the world and in Indonesia until March 2017 recorded 242,699 cases. The recorded amount does not reflect the real number in the community because HIV infection often does not show specific symptoms before entering the stage of AIDS. This study aimed to examine the application of the health belief model on adherence to antiretroviral therapy among HIV/ AIDS patients in Surakarta, Central Java.

Subject and Method: This was a cross sectional study conducted at Dr. Moewardi Hospital, Surakarta, Central Java, on February 2018. A total sample of 284 HIV/AIDS patients was selected for this study by exhaustive sampling. The dependent variable was ARV Adherence. The independent variables were perceived susceptibility, perceived severity, perceived benefits, perceived barriers, cues to action, and self-efficacy. The data were collected using a questionnaire and analyzed by a path analysis.

Results: Adherence directly increased with self-efficacy $(b=2.10 ; 95 \% \mathrm{CI}=0.85$ to $3.34 ; \mathrm{p}=$ 0.001), perceived benefit ( $\mathrm{b}=2.08$; $95 \% \mathrm{CI}=1.15$ to 3.00; $\mathrm{p}<0.001)$, and cue to action $(\mathrm{b}=3.61$; $95 \% \mathrm{CI}=0.86$ to $6.36 ; \mathrm{p}=0.010)$ but decreased with higher perceived barrier $(\mathrm{b}=2.08 ; 95 \% \mathrm{CI}=$ 1.15 to $3.00 ; \mathrm{p}<0.001)$. Adherence indirectly decreased with higher perceived severity and perceived susceptibility.

Conclusion: Self-efficacy, perceived benefit, perceived barrier, and cue to action directly affect the adherence to antiretroviral therapy. Perceived severity and perceived susceptibility indirectly affect the adherence to antiretroviral therapy.
\end{abstract}

Keywords: ARV adherence, perceived susceptibility, perceived severity, perceived benefits, perceived barriers, cues to action, self-efficacy

\section{Correspondence:}

Dyah Ayu Agustin. School of Health Sciences Kendedes, Malang, East Java.

Email: ayuagustin20@gmail.com. Mobile: +6281316337006.

\section{BACKGROUND}

HIV/ AIDS (Acquired Immune Deficiency Syndrome) is still a health problem in the world including Indonesia (Ministry of Health, 2017; WHO, 2017). Approximately 36.7 people were infected with HIV in the world (WHO, 2017) and in Indonesia until March 2017 recorded 242,699 cases (Ministry of Health, 2017). The recorded amount does not reflect the real number in the community because HIV infection often does not show specific symptoms before entering the stage of AIDS (UNAIDS, 2017).

The use of HAART (Highly Active Antiretroviral Therapy) in the treatment of HIV/ AIDS infection decreased mortality and morbidity due to HIV/ AIDS infection (Becerra et al., 2016; Yoshimura, 2017). 
Unfortunately, such antiretroviral therapy should last a lifetime of patients non-stop, because once stalled, HIV in the patient's body will soon increase in number (Darcis et al., 2017). Though the drug can also cause side effects that some patients can not tolerate, causing patients to be disobedient in taking drugs (Eckard et al., 2016; Kwarteng et al., 2017; Mattevi and Tagliari, 2017). In addition to drug sideeffects, many factors affect patient adherence to HIV/ AIDS infection in the treatment to be identified and given the solution (Croome et al., 2017; Iacob et al., 2017; Shubber et al., 2016). Non-adherence to antiretroviral treatment in addition to increasing the number of HIV in the patient's body (worsening the clinical course) will also increase HIV resistance to antiretroviral drugs (Garbelli et al., 2017; Piana et al., 2017). HIV resistance to antiretroviral drugs alone has the potential to inhibit the planned elimination of AIDS as a global health problem by 2030 (Clutter et al., 2016).

Surakarta City is one of the Central Java Province cities which has recorded the number of HIV/ AIDS infected patients as much as 2,428 people until March 2017 (Ministry of Health, 2017). A number of HIV/ AIDS infection patients performing antiretroviral therapy at VCT clinic (Voluntary Counseling and Testing) RSUD (Regional General Hospital) Dr. Moewardi in Surakarta in August 2017 were 581 patients (source: primary, unpublished). Unfortunately, there has been no evaluation and data related to such adherence in the antiretroviral therapy program, especially the determinants of patient compliance. Not only in Surakarta, as far as the researchers know there has been no publication reporting the determinants of adherence to HIV/ AIDS infection in Indonesia in taking antiretroviral drugs. Therefore, the researcher will conduct research activity to know the determinant of HIV/ AIDS infection patient in VCT RSDM in taking an antiretroviral drug with health belief model approach, a model used to predict health-related behavior (promotion) (Jones et al., 2014).

\section{SUBJECTS AND METHOD \\ 1. Study design \\ This was an analytic observational study with a cross-sectional design. The study was conducted at Dr. Moewardi Hospital, Sura- karta, Central Java, from February 2018.}

\section{Population and sample}

Population in this study was HIV/AIDS patients at Dr. Moewardi Hospital, Surakarta, Central Java. A sample of 284 in Surakarta was selected by exhaustive sampling.

\section{Study variables}

The dependent variable was ARV Adherence. The independent variables were perceived susceptibility, perceived severity, perceived benefits, perceived barriers, cue to action, and self-efficacy.

\section{Operational definition of variables}

ARV adherence was defined as the behavior of study subjects obtained through selfreport, calculation of the number of pills, exactly the time of visit, the exact dose, frequency, and percentage of the total amount of prescribed medication. The data was collected by questionnaire. Measurement scale was categorical, transformed into dichotomous coded as follows, i.e. o for non adhere and 1 for adhere.

Perceived susceptibility was defined as the perception of the study subject concerns the risk of his or her health condition. The data was collected by questionnaire. The data was collected by questionnaire. Measurement scale was continuous, transformed into dichotomous coded as follows, i.e. $\mathrm{o}$ for low and $1 \mathrm{for}$ high. 
Journal of Health Promotion and Behavior (2018), 3(1): 48-55

https://doi.org/10.26911/thejhpb.2018.03.01.05

Perceived severity was defined as a perception of the study subject about the seriousness of a disease. The data was collected by questionnaire. Measurement scale was continuous.

Perceived benefits was defined as the study subject's perception that antiretroviral therapy is beneficial. The data was collected by questionnaire. Measurement scale was continuous, transformed into dichotomous coded as follows, i.e. o for low and 1 for high.

Perceived barriers was defined as the perception of the study subject of the perceived obstacles to change behavior. The data was collected by questionnaire. Measurement scale was continuous, transformed into dichotomous coded as follows, i.e. $\mathrm{o}$ for high and 1 for low.

Cue to action was defined as a behavior was influenced by a thing that becomes a signal for the study subject to perform an action or behavior. The data was collected by questionnaire. Measurement scale was continuous, transformed into dichotomous coded as follows, i.e. o for low and 1 for high.

Self-efficacy was defined as a the subject's belief in oneself to adhere to antiretroviral therapy. The data was collected by questionnaire. Measurement scale was continuous, transformed into dichotomous coded as follows, i.e. o for low and 1 for high.

\section{Data analysis}

The result of characteristic analysis of study subject and univariate analysis in the form of categorical/ dichotomy data was described in frequency (n) and percent (\%). Bivariate analysis was performed using ChiSquare test. Multivariate analysis using path analysis with SPSS Stata program, through the following steps:
a. Model specification
b. Model identification

c. Model fit

d. Estimation

e. Model respecification

\section{Research ethics}

The research ethics clearance was obtained from the Research Committe at Dr. Moewardi Hospital. Research ethics included informed consent, anonimity, and confidentiality.

\section{RESULTS}

1. Characteristics of study subject

Table 1 showed the characteristics of the study subjects. Most of the study subjects were age >35 years, male $65.8 \%$, had education $\geq$ senior high school $69.4 \%$, and income $<$ UMR 55.3\%.

\section{Table 1. Sample characteristics}

\begin{tabular}{|c|c|c|c|}
\hline No & Characteristics & $\mathbf{n}$ & $\%$ \\
\hline \multirow[t]{3}{*}{1} & $\begin{array}{l}\text { Perceived } \\
\text { susceptibility }\end{array}$ & & \\
\hline & Low & 81 & 28.5 \\
\hline & High & 203 & 71.5 \\
\hline \multirow[t]{3}{*}{2} & Perceived beneft & & \\
\hline & Low & 49 & 17.3 \\
\hline & High & 235 & 82.7 \\
\hline \multirow[t]{3}{*}{3} & Perceived barrier & & \\
\hline & Low & 129 & 45.4 \\
\hline & High & 155 & 54.6 \\
\hline \multirow[t]{3}{*}{4} & Perceived severity & & \\
\hline & Low & 70 & 24.6 \\
\hline & High & 214 & 75.4 \\
\hline \multirow[t]{3}{*}{5} & Self-efficacy & & \\
\hline & Low & 35 & 12.3 \\
\hline & High & 249 & 87.7 \\
\hline \multirow[t]{3}{*}{6} & Cues to action & & \\
\hline & Low & 18 & 6.3 \\
\hline & High & 266 & 93.7 \\
\hline \multirow[t]{3}{*}{7} & Adherence & & \\
\hline & No adhere & 61 & 21.5 \\
\hline & Adhere & 223 & 78.5 \\
\hline
\end{tabular}

\section{Bivariate analysis}

The bivariate analysis on the Table 2 showed that perceived susceptibility, perceived severity, perceived benefit, cues to action, self-efficacy were positively affected on Adherence to antiretroviral therapy. 
Perceived barrier was negatively affected on

Adherence to antiretroviral therapy.

Table 2. The results of bivariate analysis

\begin{tabular}{|c|c|c|c|c|c|c|c|}
\hline \multirow{3}{*}{ Variable } & \multicolumn{4}{|c|}{ Adherence } & \multirow{3}{*}{$\mathbf{O R}$} & \multirow{3}{*}{$95 \%$ CI } & \multirow{3}{*}{$\mathbf{p}$} \\
\hline & \multicolumn{2}{|c|}{ No adhere } & \multicolumn{2}{|c|}{ Adhere } & & & \\
\hline & $\mathbf{N}$ & $\%$ & $\mathbf{N}$ & $\%$ & & & \\
\hline \multicolumn{8}{|l|}{ Perceived susceptibility } \\
\hline Low & 58 & 71.6 & 23 & 28.4 & 168.1 & 48.74 to & $<0.001$ \\
\hline High & 3 & 1.5 & 200 & 98.5 & 2 & 579.85 & \\
\hline \multicolumn{8}{|l|}{ Perceived beneft } \\
\hline Low & 33 & 67.3 & 16 & 32.7 & 15.25 & 7.45 to 31.19 & $<0.001$ \\
\hline High & 28 & 11.9 & 207 & 88.1 & & & \\
\hline \multicolumn{8}{|l|}{ Perceived barrier } \\
\hline Low & 5 & $3 \cdot 9$ & 124 & 96.1 & 0.07 & 0.03 to 0.19 & $<0.001$ \\
\hline High & 56 & 21.5 & 99 & 63.9 & & & \\
\hline \multicolumn{8}{|l|}{ Perceived severity } \\
\hline Low & 46 & $65 \cdot 7$ & 24 & $34 \cdot 3$ & 25.43 & 12.37 to & $<0.001$ \\
\hline High & 15 & 7.0 & 199 & 93.0 & & 52.26 & \\
\hline \multicolumn{8}{|l|}{ Self-efficacy } \\
\hline Low & 27 & 77.1 & 8 & 22.9 & 21.34 & 8.96 to & $<0.001$ \\
\hline High & $13 \cdot 7$ & 13.7 & 215 & 86.3 & & 50.84 & \\
\hline \multicolumn{8}{|l|}{ Cues to action } \\
\hline Low & 17 & 94.4 & 1 & 5.6 & $85 \cdot 77$ & 11.13 to & $<0.001$ \\
\hline High & 44 & 16.5 & 222 & 83.5 & & 661.33 & \\
\hline
\end{tabular}

\section{Path analysis}

The data were analysis using Stata 13 program. The observed variables were 6 , endogenous variables were 3 , exogenous variables were 6 , and parameters were 6 . Degree of freedom formula, as follows:

$\mathrm{df}=($ observed variable $\mathrm{x}$ (observed variable +1$)) / 2-($ endogenous variable+ exogenous variable+ parameter)

$$
\begin{aligned}
& =(6 \times(6+1)) / 2-(3+6+6) \\
& =21-15=6
\end{aligned}
$$

Degree of freedom was over identified and path analysis can be done. Structural model with estimation of path analysis showed in Figure 1. The results of path analysis showed in Table 2.

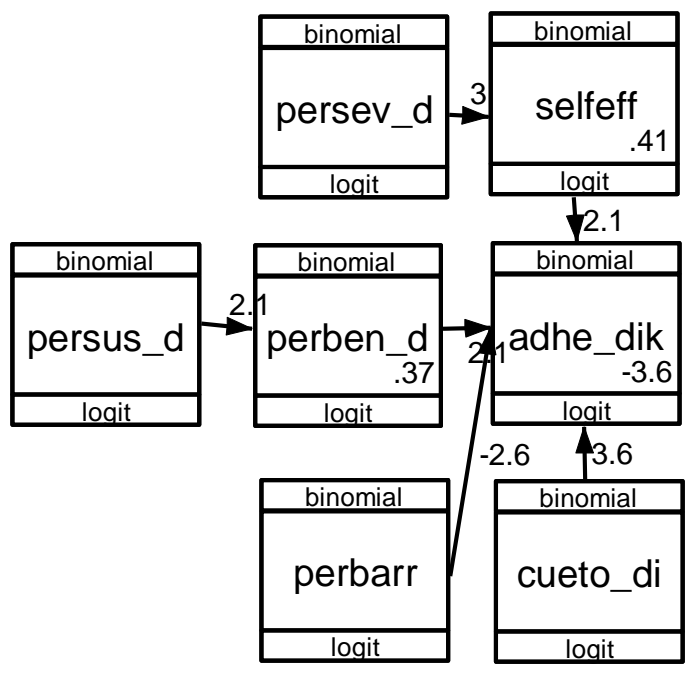

Figure 1. Structural model after estimation 
Journal of Health Promotion and Behavior (2018), 3(1): 48-55

https://doi.org/10.26911/thejhpb.2018.03.01.05

Table 2. The results of path analysis on adherence to antiretroviral therapy among HIV/ AIDS patient

\begin{tabular}{|c|c|c|c|c|c|c|}
\hline \multirow{2}{*}{\multicolumn{2}{|c|}{ Dependent variable }} & \multirow{2}{*}{$\begin{array}{l}\text { Independent } \\
\text { variable }\end{array}$} & \multirow{2}{*}{$\begin{array}{c}\text { Path } \\
\text { Coefficient }\end{array}$} & \multicolumn{2}{|c|}{$95 \% \mathrm{CI}$} & \multirow{2}{*}{$\mathbf{p}$} \\
\hline & & & & Lower & Upper & \\
\hline \multicolumn{7}{|l|}{ Direct Effect } \\
\hline \multirow[t]{4}{*}{ Adherence } & $\leftarrow$ & Self-efficacy & 2.10 & 0.85 & $3 \cdot 34$ & 0.001 \\
\hline & $\leftarrow$ & Perceived barrier & -2.55 & -3.70 & -1.41 & $<0.001$ \\
\hline & $\leftarrow$ & Perceived beneft & 2.08 & 1.15 & 3.00 & $<0.001$ \\
\hline & $\leftarrow$ & Cues to action & 3.61 & 0.86 & 6.36 & 0.010 \\
\hline \multicolumn{7}{|l|}{ Indirect Effect } \\
\hline Self-efficacy & $\leftarrow$ & Perceived severity & 2.98 & 2.09 & 3.87 & $<0.001$ \\
\hline $\begin{array}{l}\text { Perceived benefit } \\
\text { n observation }\end{array}$ & $\begin{array}{l}\leftarrow \\
=\end{array}$ & $\begin{array}{l}\text { Perceived susceptibility } \\
284\end{array}$ & 2.08 & 1.41 & 0.76 & $<0.001$ \\
\hline $\begin{array}{l}\text { Log Likelihood } \\
\text { BIC } \\
\text { AIC }\end{array}$ & $\begin{array}{l}= \\
= \\
=\end{array}$ & $\begin{array}{l}-271.53 \\
593.89 \\
561.05\end{array}$ & & & & \\
\hline
\end{tabular}

These values indicate that path analysis model in Figure 1 meets the criteria specified and expressed in accordance with the empirical data.

1. Factors directly affecting on adherence to antiretroviral therapy

Adherence to antiretroviral therapy in HIV/ AIDS patient was directly affected by selfefficacy, perceived barrier, perceived benefit, and cue to action.

a. There is a direct effect of self-efficacy on adherence to antiretroviral therapy and statistically significant. High self-efficacy has a logodd scores for medication adherence of 2.10 units higher than low self-efficacy $(b=2.10 ; 95 \% \mathrm{CI}=0.85$ to $3.34 ; \mathrm{p}=0.001$ ).

b. There is a direct effect of perceived barrier on adherence to antiretroviral therapy and statistically significant. High perceived barrier have a logodd score of medication adherence of 2.55 units higher than a low perceived barrier $(\mathrm{b}=$ $-2.55 ; 95 \% \mathrm{CI}=-3.70$ to $-1.41 ; \mathrm{p}<0.001)$.

c. There is a direct effect of perceived benefit on adherence to antiretroviral therapy and statistically significant. Higher perceived benefits have a loggodd score of 1.45 units higher than low perceived benefit $(\mathrm{b}=2.08$; $95 \% \mathrm{CI}=$ 1.15 to $3.00 ; \mathrm{p}<0.001$ ).

$\mathrm{d}$. There is a direct effect cues to action on adherence to antiretroviral therapy and statistically significant. The high cues to action have a logodd score of 3.13 units higher than low cues to action $(b=3.61$; $95 \% \mathrm{CI}=0.86$ to $6.36 ; \mathrm{p}=0.010$ ).

2. Factors indirectly affecting on adherence to antiretroviral therapy

Adherence to antiretroviral therapy in HIV/ AIDS patient was indirectly affected by perceived severity and perceived susceptibility.

a. There is a effect of perceived severity effect on adherence to antiretroviral therapy through self-efficacy and statistically significant. A high perceived severity have a logodd score of 2.98 unit self-efficacy higher than a low perceived severity $(\mathrm{b}=2.98 ; 95 \% \mathrm{CI}=2.09$ to 3.87 ; $\mathrm{p}<0.001)$.

b. There is a effect of perceived susceptibility on adherence to antiretroviral therapy through perceived benefit and statistically significant. High perceived susceptibility have a logodd score of 2.08 higher perceived benefit than low 
perceived susceptibility ( $b=2.08 ; 95 \%$ $\mathrm{CI}=1.41$ to $0.76 ; \mathrm{p}<0.001$ ).

\section{$\frac{\text { CONCLUSION }}{\text { 1. The Effect of Self-Efficacy on Adhe- }}$ rence to Antiretroviral Therapy Among HIV/ AIDS Patients.}

The result of this study indicated that high self-efficacy may improve adherence to antiretroviral therapy. Self-efficacy is a selfconfidence of an individual's ability to well perform a certain action so that he tried to show the best thing he could do in order to achieve the maximum result (Bandura, 1977 in Sulaeman, 2016). In the health belief model, the high perception of health threat will increase the self-efficacy of individuals, in this case, individuals being able to manage the aspects of his efficacy. If individuals do not believe or confident that they can carry out behavior change, then they cannot do it (Simpson, 2015). Self efficacy will give impact to treatment disobedience. Patients' knowledge concerning to antiretroviral therapy needs to be supported by HIV/ AIDS patients' belief of being able or capable to undergo antiretroviral therapy obediently so that it will not drop out. Self-efficacy can be established from the surrounding environment.

\section{The Effect of Perceived Barrier on} Adherence to Antiretroviral Therapy Among HIV/ AIDS Patients

The result of this study indicated that high perceived barrier may decrease adherence to antiretroviral therapy. Based on Health Belief Model concept individuals have perception concerning the experienced barriers that it may influence individuals to not change their behavior (Burke, 2015). Perceived barrier refers to an individual's assessment of the perceived barriers to behavior change (Janz and Backer 1984 in Sulaeman, 2016). Barriers may reduce adherence to antiretroviral therapy. In broad line the barriers are financial and social barrier. Further, when patient's belief toward barriers or obstacles is reduced or disappears then the adherence will be increasing. Geographic location also influence patients' adherence to antiretroviral therapy. The road condition makes it difficult to go to healthcare facilities or because the distance is too far makes HIV/ AIDS patients are reluctant to have medical examination in reliable health care facilities.

\section{The Effect of Perceived Benefit on}

Adherence to Antiretroviral Therapy Among HIV/ AIDS Patients

The result of this study indicated that high perceived benefit may improve adherence to antiretroviral therapy. Perceived benefit refers to the individual assessment of efficacy to reduce the risk of disease (Resenstock 1974 in Sulaeman, 2016). In accordance with Health Belief Model an individual has a perception on the benefit to be experienced if conducting behavior change (Burke, 2015). Direct association between perceived benefit and adherence to antiretroviral therapy was positive and significant. Patients who believe that the undergone treatment will give positive impact for themselves will be more obedient toward the treatment. In addition, someone with high perception toward the benefit of antiretroviral therapy will reduce any obstacles or barriers they experience. Perceived benefit may get improved by making excellent communication between health personnel and HIV/ AIDS patients. It is expected that with good communication, health personnel may give the appropriate education about the benefits and importance of regular treatment.

4. The Effect of Cues to Action on Adherence to Antiretroviral Therapy Among HIV/ AIDS Patients

The result of this study indicated that high cues for action can improve adherence to 
antiretroviral therapy. Cues to Action is a part of Health Belief Model which is anything that encourage decision in changing behavior (Horne et al., 2013). Good knowledge concerning HIV/ AIDS needs to be accompanied by the support from closest people. HIV/ AIDS patients who live alone and far from their family or neighbors will be more likely to stop antiretroviral therapy before its time.

\section{The Effect of Perceived Severity on} Adherence to Antiretroviral Therapy Among HIV/ AIDS Patients through Self-Efficacy

The result of this study indicated that high perceived severity can increase the likelihood of high self-efficacy. Perceived severity were a form of assessment of the severity of health problems and its potential consequences (Janz et al., 1984; Glanz cit Sulaeman, 2016). Health Belief Model elaborates perceived severity within an individual and may influence individual in taking action (Simpson, 2015). Individual action to conduct treatment and prevention for a disease will be encouraged by the severity of the disease. The bigger the risk of the disease the more likely the individual feel threatened. The threat encourages individual action to conduct prevention and treatment for the disease.

6. The Effect of Perceived Susceptibility on Adherence to Antiretroviral Therapy Among HIV/ AIDS Patients through Perceived Benefit The result of this study indicated that High perceived susceptibility may increase the likelihood of high perceived susceptibility. Rosenstock et al., (1988) stated that Health Belief Model is one of the oldest model that discuss the preparation to conduct health behavior based on several individual beliefs and perception. The study result was in accordance with the previous finding that mentioned individual belief role in HBM influenced individual decision in increasing health behaviors, one of them was adherence to antiretroviral therapy.

\section{REFERENCE}

Becerra JC, Bildstein LS, Gach JS (2016). Recent Insights into the HIV/AIDS Pandemic. Microbial Cell, 3(9): 451475.

Burke E (2015). Ten-Year Change in Blood Pressure Levels and Prevalence of Hypertension in Urban and Rural Cameroon. BMC Cardiovascular Disorders, 16(1): 1461-1473

Clutter DS, Jordan MR, Bertagnolio S, Shafer RW. 2016. HIV-1 Drug Resistance and Resistance Testing. Infection, Genetics and Evolution, 46: 292-307.

Garbelli A, Riva V, Crespan E, Maga G (2017). How to Win the HIV-1 Drug Resistance Hurdle Race: Running Faster or Jumping Higher? Biochemical Journal, 474(10): 1559-1577.

Horne R, Chapman SCE, Parham R, Freemantle N, Forbes A, Cooper V (2013). Understanding Patients' AdherenceRelated Beliefs about Medicines Prescribed for Long-Term Conditions: A Meta-Analytic Review of The Necessity-Concerns Framework.PLoS ONE, 8(12): 1-24.

Jones CJ, Smith H, Llewellyn C (2014). Evaluating the Effectiveness of Health Belief Model Interventions in Improving Adherence: A Systematic Review. Health Psychology Review, 8(3): 253-269.

Kenmenkes RI, 2017. Laporan Kementerian Kesehatan Triwulan I. http://www.aidsindonesia.or.id/ckuploads/files/Laporan\%2OHIV\%2OAIDS\%20TW\%2 01\%202017.pdf. Accessed August, 20 2017. 
Kwarteng A, Ahuno ST, Kwakye-Nuako G (2017). The Therapeutic Landscape of HIV-1 via Genome Editing. AIDS Research and Therapy, 14(1): 32. doi: 10.1186/s12981-017-0157-8.

Iacob SA, Iacob DG, Jugulete G (2017). Improving the Adherence to Antiretroviral Therapy, a Difficult but Essential Task for a Successful HIV Treatment-Clinical Points of View and Practical Considerations. Frontiers in Pharmacology, 8: 831. doi: 10.3389/fphar.2017.00831.eCollection 2017.

Mattevi VS, Tagliari CF (2017). Pharmacogenetic Considerations in the Treatment of HIV. Pharmacogenomics, 18(1): 85-98.

Simpson V (2015). Models and Theories to Support Health Behavior Intervention and Program Planning. Health and Human Sciences, 1-5

Shubber Z, Mills EJ, Nachega JB, Vreeman R, Freitas M, Bock P, Nsanzimana S,
Penazzato M, Appolo T, Doherty M, Ford N (2016). Patient-Reported Barriers to Adherence to Antiretroviral Therapy: A Systematic Review and Meta-Analysis. PLoS Medicine, 13(11): e1002183. doi: 10.1371/journal.pmed.1002183.

UNAIDS (2017). Overview - Indonesia. http://www.unaids.org/en/regionsco untries/countries/indonesia. Accessed August 20, 2017.

WHO (2017). Data and Statistics. http://www.who.int/hiv/data/en/. Accessed August 20, 2017.

Yoshimura K. 2017. Current Status of HIV/AIDS in the ART Era. Journal of Infection and Chemotherapy, 23(1): 12-16. 